\title{
Interdisciplinary Research and Application of GIS and Remote Sensing in Land Use and Land Cover Change: A Review
}

\author{
Jialiang Zhong ${ }^{\mathrm{a}}$, Dafang $\mathrm{WU}^{\mathrm{b}}$, Chao ZHU \\ School of Geographical Sciences, Guangzhou University, Guangzhou, Guangdong, China \\ a Author email: 495841810@qq.com, ${ }^{b}$ Corresponding author email: wudaf2004@163.com, ${ }^{\mathrm{C} e m a i l:}$ \\ 1641497860@qq.com
}

Keywords: Land use/land cover change, China, review.

Abstract. LUCC (land use and land cover change) has become one of the hotspots in global change research. Through literature induction, there are some differents between Chinese and foreign scholars in research direction and technical methods. Chinese scholars focus on researching changing laws, driving forces and ecological effects of LUCC, but foreign scholars pay more attention to its social effects, such as city expansion and distribution of public infrastructure land. Chinese scholars use simple mathematical statistical methods to descripe LUCC, and foreign scholars tend to establish models to analyze and predict its changes, and do well in interdisciplinary research, GIS and remote sensing techniques.

\section{Introduction}

LUCC (land use and land cover change) refers to the type of land that emphasizes economic attributes and the surface environment of land that emphasizes the natural properties change. With the advancement of the urbanization process, land use and development in developed and developing countries show a tendency to expand, which brings a series of environmental problems. International scholars began to research LUCC, aimed at implementing sustainable development. In recent 20 years, with the deepening of research and the popularization of technical methods, especially GIS and remote sensing applications, LUCC research has made good progress and found that its driving factors include human activities, especially and natural factors. Its internal mechanism is complex, involving the nature of disciplines, social disciplines and others. This paper summarizes the relevant literature worldwide, analyzing and summarizing the studies of Chinese scholars and foreign scholars in LUCC, and points out the differences between them, and provides recommendations for Chinese scholar in their future research.

\section{Related research of LUCC in China}

In the research of LUCC (land use and land cover change), Chinese scholars mainly focus on pattern of land cover and landscape change (Gong and Xia, 2007; Liu et al., 2016), description the land use change in the temporal and spatial evolution, and analysis of its driving force (Mao et al., 2009). Besides, relationship between LUCC and natural ecological environment, including force between water and sand (Liu et al., 2016), temperature change (Zhai et al., 2014), and changes in soil organic carbon (Yang et al., 2016). Furthermore, they calculate changes in the value of ecosystem services based on LUCC (Zhang and Qian, 2010). These studies are small-scale, limited to a natural component, research on local ecosystems is little. For example, the research of LUCC and Dadu River forest system degradation (Yan et al., 2005) need to be carried out a lot of field work, with a certain degree of difficulty.

In the discussion of specialized LUCC research techniques, Chinese scholars have studied less, only an example of establishing models to meet the demand for land use/cover pseudo-change plots due to spatial registration errors (Gao et al., 2014). Most Chinese scholars are based on remote sensing images, preferring to use descriptive statistics, correlation analysis, regression analysis, and so on. In recent years, Chinese scholars have tried to use the method that foreign scholars have put forward, 
such as OMR (Observation Minus Reanalysis), to explore the specific issues, researching the relationship between LUCC and temperature changes in Inner Mongolia Plateau (Zhai et al., 2014).

\section{Related research of $\mathrm{LUCC}$ in other countries}

The research of LUCC (land use and land cover change) by foreign scholars is concerned with landscape changes (Jenerette and $\mathrm{Wu}, 2001$ ), trend of LUCC and analysis of its driving force (Gupta, 2014). Besides, the research focuses on the interaction between LUCC and natural ecological environments, such as the degree of ecosystems degradation (Wasige et al., 2013), banlance among urban development, oil palm cultivation and forest protection (Nourqolipour et al., 2015). It is noteworthy that foreign scholars consider more about the relationship between LUCC and socioeconomic, such as the economic function of land use types (Salvati and Carlucci, 2014; Luus and Kelly, 2008), the expansion of the city (Seto et al., 2005; Galdavi et al., 2013), distribution of public infrastructure land (Ottensmann, 2003), and industrial enterprise expansion (Chapple, 2014).

Foreign scholars also prefer to discuss the improvement and practical application of remote sensing interpretation techniques (Levin, 2013; Lodhi et al., 2014; Babamaaji and Lee, 2014; Belgiu et al., 2014), including the method of correlation coefficient(CC), universal image quality Index (UIQI), Maximum Likelihood Classification (Sanli et al., 2016) and Binary Partition Tree (BPT) (Li et al., 2015).

In the application of technology, foreign scholars are more skilled than Chinese scholars. GIS spatial analysis and mathematical modeling can always be seen in their research for the reason that the model can be better to predict the future. The most commonly used methods and models include post-classification comparison method (Galdavi et al., 2013), cellular automata model (CA), supply/demand/allocation model, the Western Futures Model (Claggett et al., 2004), Markov chain, Multi-criteria evaluation (MCE) (Nourqolipour et al., 2015), and Logistic regression (Fang et al., 2007).

More importantly, foreign scholars will conduct interdisciplinary research. They research LUCC impact on the water environment associating geography with chemical (Fučík et al., 2014).And reveal the pattern and driving force of shoreline erosion associating geography with physics (Samanta and Paul, 2016). They also try to evaluate value of brownfields (megasites) for re-development and utilization associating geography with economics (Schädler et al., 2012).

\section{Conclusions}

Pay Attention to Social and Economic Environment. Throughout the domestic and international research, research area are more concentrated in the driving force of active regions or ecologically fragile areas, such as Tarim, China (Yang et al., 2016), central Arizona-Phoenix region, USA (Jenerette and $\mathrm{Wu}, 2001$ ), these areas are deserve to be concerned for higher research value. Chinese scholars pays more attention to the ecological environment than the social and economic environment. Large population in China, but land resources "rigid shortage". It requires us that using land resource intensively. The combination of research results and social realities can better reflect the value of its results, guiding decision makers to make reasonable decisions, and play the potential economic benefits of land.

Improve Technical Methods. Chinese research focuses on the mechanism and effect of land use change. Foreign research focuses on the driving factors and simulation of land use change. Chinese research lack of habits and abilities to build model ( $\mathrm{Li}$ et al., 2015). Meanwhile, the study, Chinese scholars towards foreign research model and method, are not enough depth. Chinese scholars lack of innovative research model (Yuan, 2016). The reason may be the data source is not wide, and it is difficult to form the system index system, which is reflected in more dependent on yearbook data.

Make Good Use of GIS and Remote Sensing. GIS technology and remote sensing can provide great help for the research of LUCC (land use and land cover change). GIS can obviously improve the precision and efficiency of research. Remote sensing interpretation technology can help researchers 
obtain accurate data at a faster rate. Studying on GIS and forming a unified classification standard in remote sensing interpretation can make the research of LUCC more convenient and comparable, when different scholars conduct the research in the same area, due to the consistency of data sources.

Conduct Interdisciplinary Research. In the study of the ecological environment, due to operational capacity and the limitations of the actual situation, Chinese scholars often conduct a research simply and avoid talking about too many factors (Yang et al., 2016). In this regard, foreign Scholars' research can use other disciplines (chemistry) to analyze the problem exhaustively (Fučík et al., 2014). The study of LUCC is complex and requires complementary multidisciplinary knowledge. In the future, Chinese scholars can do more in this regard, which will help to analyze the problem more thoroughly.

\section{Acknowledgements}

This work was financially supported by National Natural Science Foundation of China (41101078); Innovation Project of Guangdong Provincial Department of Education (2014KTSCX090); Guangzhou "Twelfth Five-Year Plan" Philosophy and Social Sciences Project in 2015 (15Q28); College Students' Innovative Training Program of Guangdong Provincial Department of Education (201511078019, CX2015025).

\section{References}

[1] J. Z. Gong and B.C. Xia. 2007. Temporal-spatial grading diversification of land-cover at landscape level in Guangzhou since 1990. Acta Geographica Sinica, 62(2): 181-190. (in Chinese)

[2] X. J. Liu, Z. B. Li, P. Li, et al. 2016. Land use/cover change based relationship between landscape, runoff, and sedimentation. Acta Ecologica Sinica, 36(18): 5691-5700. (in Chinese)

[3] J.X. Mao, X.P. Yan, Z.G. Li and H. Huan. 2009. A comprehensive research on the physical and human dimensions of land use changes under rapid urbanization in Shenzhen city. Journal of Natural Resources, 24(3): 523-535. (in Chinese)

[4] J. Zhai, Q. Q. Shao and Y. Y. Liu. 2014. Impact analysis of climate change from land use/cover change in Inner Mongolia Plateau. Journal of Natural Resources, 29(6): 968--978. (in Chinese)

[5] Y. H. Yang, Y. N. Chen, W. H. Li and Y. Wang. 2016. Effects of land use/cover change on soil organic carbon storage in the main stream of Tarim River. China Environmental Science, 36(9): 2784-2790. (in Chinese)

[6] Y. X. Zang and H. S. Qian. 2010. Effect of land use change on ecosystem services value of the urban fringe in Guangzhou city. Guangdong Agricultural Sciences, (9): 294-304. (in Chinese)

[7] J. Z. Yan, Y. L. Zhang, W. Q. Bai, et al. 2005. Study on land cover change based on vegetation succession-forest cutting, renewal and degradation in the upper reaches of Dadu river. Journal of Earth Science, 35(11): 1060-1073. (in Chinese)

[8] X. Z. Gao, H. J. Liu, B. L. Li and Y. C. Yuan. 2014. A new method to detect false change polygons in land use/cover change map based on symmetric theory model. Journal of Geo-information Science, 16(5): 784-789. (in Chinese)

[9] G. D. Jenerette and J. G. Wu. 2001. Analysis and simulation of land-use change in the central Arizona-Phoenix region, USA. Landscape Ecology, 16, 611-626.

[10]R. Gupta. 2014. The pattern of urban land-use changes: A case study of the Indian cities. Environment and Urbanization Asia, 5(1), 83-104. 
[11] J. E. Wasige, T. A. Groena, E. Smalinga and V. Jetten. 2013. Monitoring basin-scale land cover changes in Kagera basin of Lake Victoria using ancillary data and remote sensing. International Journal of Applied Earth Observation and Geoinformation, 21, 32-42.

[12] R. Nourqolipour, A. R. B. M. Shariff, N. B. Ahmad, et al.. 2015. Multi-objective-based modeling for land use change analysis in the South West of Selangor, Malaysia. Environmental Earth Sciences, 74, 4133-4143.

[13]L. Salvati and M. Carlucci. 2014. Urban growth and land-use structure in two Mediterranean regions: An exploratory spatial data analysis. SAGE Open, 4(4), 1-13.

[14]K. A. Luus and R. E. J. Kelly. 2008. Assessing productivity of vegetation in the Amazon using remote sensing and modelling. Progress in Physical Geography, 32(4), 363-377.

[15]K. C. Seto and M. Fragkias. 2005. Quantifying spatiotemporal patterns of urban land-use change in four cities of China with time series landscape metrics. Landscape Ecology, 20, 871-888.

[16]S. Galdavi, M. Mohammadzadeh, A. Salmanmahiny and A. N. Nejad. 2013. Urban change detection using multi-temporal remotely sensed imagery (Case study: Gorgan Area, Northern Iran). Environment and Urbanization Asia, 4(2), 339-348.

[17]J. R. Ottensmann. 2003. Land use in Central Indiana Model and the relationships of public infrastructure to urban development. Public Works Management \& Policy, 8(1), 62-76.

[18]K. Chapple. 2014. The highest and best use? Urban industrial land and job creation. Economic Development Quarterly, 28(4), 300-313.

[19]G. Levin. 2013. Applying parcel-specific land-use data for improved monitoring of semi-natural grassland in Denmark. International Environ Monit Assess, 185, 2615-2625.

[20] M. S. Lodhi, P. K. Samal, S. Chaudhry, et al.. 2014. Land cover mapping for Namdapha National Park (Arunachal Pradesh), India using harmonized land cover legends. Indian Society of Remote Sensing, 42(2), 461-467.

[21]R. A. Babamaaji and J. Lee. 2014. Land use/land cover classification of the vicinity of Lake Chad using NigeriaSat-1 and Landsat data. Environmental Earth Sciences, 71, 4309-4317.

[22] J. E. Wasige, T. A. Groena, E. Smalinga and V. Jetten. 2014. Quantitative evaluation of variations in rule-based classifications of land cover in urban neighbourhoods using WorldView-2 imagery. ISPRS Journal of Photogrammetry and Remote Sensing, 87, 205-215.

[23]F. B. Sanli1, S. Abdikan, M. T. Esetlili and F. Sunar. 2016. Evaluation of image fusion methods using PALSAR, RADARSAT-1 and SPOT images for land use/ land cover classification. Indian Society of Remote Sensing, 1-11.

[24]M. Li, W. Bijker, A. Stein. 2015. Use of Binary Partition Tree and energy minimization for object-based classification of urban land cover. ISPRS Journal of Photogrammetry and Remote Sensing, 102, 48-61.

[25] P. R. Claggett, C. A. Jantz, S. J. Goetz and C. Bisland. 2004. Assessing development pressure in the chesapeake bay watershed: an evaluation of two land-use change models. Environmental Monitoring and Assessment, 94, 129-146.

[26] S. F. Fang, G. Z. Gertner and A. B. Anderson. 2007. Prediction of multinomial probability of land use change using a bisection decomposition and logistic regression. Landscape Ecology, 22, 419-430. 
[27]P. Fučík, P. Novák and D. Žižala. 2014. A combined statistical approach for evaluation of the effects of land use, agricultural and urban activities on stream water chemistry in small tile-drained catchments of South Bohemia, Czech Republic. Environmental Earth Sciences, 72, 2195-2216.

[28]S. Samanta and S. K. Paul. 2016. Geospatial analysis of shoreline and land use/land cover changes through remote sensing and GIS techniques. Modeling Earth Systems and Environment, 2, 108.

[29]S. Schädler, M. Morio, S. Bartke and M. Finkel. 2012. Integrated planning and spatial evaluation of megasite remediation and reuse options. Journal of Contaminant Hydrology, 127, 88-100.

[30]J. Y. Li, J. Lin and S. X. Liu. 2015. Progress review on land sciences research in 2014 and prospects for 2015: Sub-report of land use and planning. China Land Sciences, 29(3): 3-12. (in Chinese)

[31]Z. K. Yuan. 2016. Review of land use/land cover change. Gansu Agricultural Science and Technology, (9): 73-77. (in Chinese) 